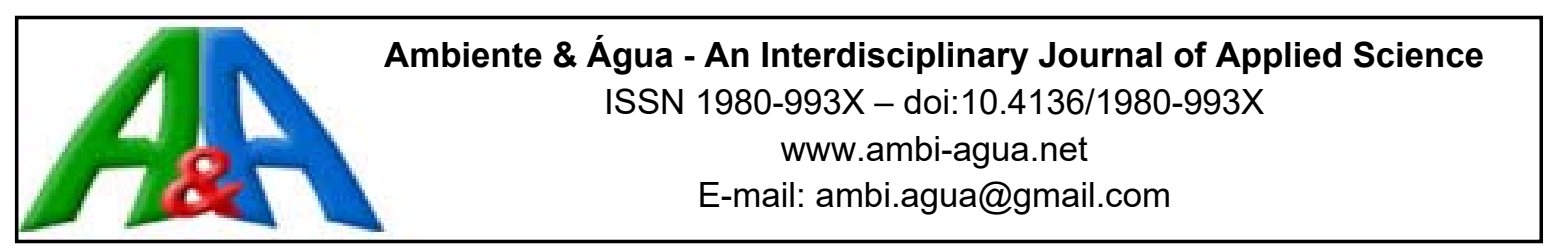

\title{
Estudo da tratabilidade de lixiviado gerado em um aterro controlado
}

\author{
doi:10.4136/ambi-agua.1957 \\ Received: 15 jun. 2016; Accepted: 18 Feb. 2017

\section{Daniela Vidal Vasconcelos; Larissa Loureiro Salgueiro Silva; Igor Lopes Guerra; Juacyara Carbonelli Campos*}

\author{
Universidade Federal do Rio de Janeiro (UFRJ), Escola de Química, \\ Rio de Janeiro, RJ, Brasil \\ Departamento de Processos Inorgânicos \\ *Autor correspondente: e-mail: juacyara@eq.ufrj.br, \\ dvvasconcelos@poli.ufrj.br, larissaloureiross@hotmail.com, \\ ilopesguerra@gmail.com
}

\section{RESUMO}

O presente trabalho avaliou os processos de coagulação/floculação, adsorção em carvão ativado em pó (CAP) e reação com Fenton para redução da concentração dos poluentes e aumento da biodegradabilidade do lixiviado. No processo de coagulação/floculação foram avaliados o pH (4 a 8) e a concentração de cloreto férrico (100 a $\left.600 \mathrm{mg} \mathrm{L}^{-1}\right)$. No processo de adsorção em CAP, foram avaliadas as concentrações de $0,1-5,0 \mathrm{~g} \mathrm{~L}^{-1}$ de CAP, e na reação com Fenton, foram avaliadas as relações DQO: $\mathrm{H}_{2} \mathrm{O}_{2}$ [1:0,5, 1:1, 1:2 e 1:5], além das relações $\mathrm{Fe}: \mathrm{H}_{2} \mathrm{O}_{2}$ [1:3, 1:5 e 1:10]. Nas melhores condições obtidas, foi avaliada a biodegradabilidade aeróbia dos efluentes tratados pelo método de Zahn-Wellens. O resultado do processo de coagulação/floculação foi de $22,9 \%$ de remoção da DQO e $64 \%$ de COT, utilizando 300 mg L' ${ }^{1}$ de coagulante em pH 4. Na adsorção em CAP, foram obtidas remoções de 69\% da DQO, utilizando $5 \mathrm{~g} \mathrm{~L}^{-1}$ de carvão. Na reação de Fenton, foram alcançadas remoções de $82,3 \%$ de DQO (para DQO: $\mathrm{H}_{2} \mathrm{O}_{2}=1: 2$ e $\mathrm{Fe}: \mathrm{H}_{2} \mathrm{O}_{2}=1: 3$ ). Os resultados de biodegradabilidade aeróbia mostraram que apenas o lixiviado tratado com Fenton apresentou uma biodegradabilidade de 12 pontos percentuais maior em relação ao bruto, mostrando a sua potencialidade como pré-tratamento ao processo biológico.

Palavras-chave: biodegradabilidade aeróbia, carvão ativado, coagulação/floculação, Reativo de Fenton.

\section{Treatability study of leachate generated in a controlled landfill}

\begin{abstract}
This study evaluated the processes of coagulation/flocculation, activated carbon adsorption and reaction with Fenton to reduce the concentration of pollutants and increase aerobic biodegradation of leachate so that it can be treated by biological process. For the process of coagulation / flocculation, $\mathrm{pH}$ (4 to 8) and the concentration of ferric chloride (100 to $600 \mathrm{mg} \mathrm{L}^{-1}$ ) were evaluated. For the adsorption on activated carbon (PAC) process, CAP concentrations of 0.1 and $5.0 \mathrm{~g} \mathrm{~L}^{-1}$ were evaluated; and for Fenton reaction, $\mathrm{COD}: \mathrm{H}_{2} \mathrm{O}_{2}$ ratio[1: 0.5, 1: 1, 1: 2 and 1: 5] and $\mathrm{Fe}: \mathrm{H}_{2} \mathrm{O}_{2}$ [1:3, 1: 5 and 1:10] were evaluated. The aerobic biodegradation of treated leachate by Zahn-Wellens method was evaluated under the best-
\end{abstract}


obtained conditions. The results for coagulation/flocculation was $22.9 \%$ removal of COD and $64 \%$ of TOC, using $300 \mathrm{mg} \mathrm{L}^{-1}$ of coagulant and $\mathrm{pH}$ equal to 4 . For the adsorption on activated carbon, removal of $69 \%$ of COD was reached using $5 \mathrm{~g} \mathrm{~L}^{-1} \mathrm{PAC}$. For Fenton reaction, removal of $82.3 \%$ for COD was reached (for COD: $\mathrm{H}_{2} \mathrm{O}_{2}=1: 2, \mathrm{Fe}: \mathrm{H}_{2} \mathrm{O}_{2}=1: 3$ ). The results of aerobic biodegradability showed that only Fenton-treated leachate could increase biodegradability by 12 percentage points compared with raw leachate. The results showed the potential of the Fenton process as a pre-treatment to the biological process.

Keywords: activated carbon, aerobic biodegradability, coagulation/flocculation, Fenton reaction.

\section{INTRODUÇÃO}

O lixiviado de aterro sanitário pode ser definido como uma mistura de líquidos proveniente da umidade natural que ocorre dentro e fora da pilha de resíduos, da água presente nos materiais depositados, da atividade microbiana e da água de infiltração, acrescentando-se os materiais dissolvidos ou suspensos que foram carreados no processo de lixiviação (Sá et al., 2012).

O uso de processos biológicos para o tratamento de lixiviado é recorrente, sendo o sistema de lodos ativados o mais aplicado devido ao amplo conhecimento das condições e à facilidade de operação. No entanto, conforme o tempo de operação do aterro, há um aumento do teor de matéria orgânica recalcitrante do lixiviado, havendo necessidade de pré-tratamento por processos físico-químicos (Cheibub et al., 2014).

Alguns estudos feitos nos últimos cinco anos pelos pesquisadores Ferreira e Campos (2014), Gewehr (2012), Cheibub et al. (2014) e Li et al. (2010) utilizaram o processo de coagulação/floculação com coagulante cloreto férrico para o tratamento de lixiviados dos seguintes aterros, respectivamente: Gericinó/RJ, Porto Alegre/RS, Gramacho/RJ e Shuangkou Town/China. Esse coagulante é o mais observado na literatura no tratamento de lixiviados devido à forte interação com as substâncias húmicas presentes no efluente (Cheibub et al., 2014).

Ferreira e Campos (2014) utilizaram $500 \mathrm{mgFe}^{+3} \mathrm{~L}^{-1} \mathrm{em}$ um lixiviado com $1.981 \mathrm{mg} \mathrm{L}^{-1}$ de DQO (Demanda Química de Oxigênio) e obtiveram 60\% de eficiência de remoção. Com uma concentração aproximadamente duas vezes maior de $\mathrm{Fe}^{3+}$ (1.102 $\left.\mathrm{mg} \mathrm{L}^{-1}\right)$, Gewehr (2012) atingiu o mesmo nível de eficiência (63\%) para um lixiviado que apresentava DQO de 4.798 $\mathrm{mg} \mathrm{L}^{-1}$. Nesse sentido, a natureza do lixiviado (tipo de resíduo, operação do aterro, clima entre outras variáveis) são definitivas para a eficiência de tal processo (Cheibub et al., 2014).

O carvão ativado (CA) é um adsorvente bastante utilizado em tratamentos de efluentes, pois apresenta características capazes de remover parte do material orgânico dissolvido remanescente de outros tratamentos (Metcalf \& Eddy, 2003). Estudos realizados por Maia (2012) e Cotman e Gotvajn (2010), utilizando adsorção em carvão ativado em pó (CAP) como pré-tratamento do lixiviado do Aterro Metropolitano de Gramacho (RJ) e de um aterro na Eslovênia, respectivamente, mostraram que podem ser alcançadas eficiências de remoção de DQO de $80 \%$ e $86 \%$, quando utilizadas dosagens de 10 e $50 \mathrm{~g} \mathrm{~L}^{-1}$ de CAP, respectivamente.

Os Processos Oxidativos Avançados (POAs) têm como objetivo principal a formação de oxidantes fortes, como é o caso da radical hidroxila, $\mathrm{OH}^{\bullet}\left(\mathrm{EH}^{0}=2,8 \mathrm{~V}\right)$, o qual irá oxidar a matéria orgânica em compostos mais simples. Existem diversos tipos de POA, contudo, é constante a utilização da reação de Fenton para o tratamento de lixiviados, pois neste caso podem ocorrer dois fenômenos: a oxidação e a adsorção da matéria orgânica no lodo formado (Deng e Egnlehardt, 2006). Assim, na reação de Fenton o peróxido de hidrogênio é adicionado ao efluente em presença de um sal de ferro, gerando $\mathrm{OH}^{\bullet}$ (Fenton, 1894). Essa técnica é capaz de 
tornar os compostos mais sensíveis ao tratamento biológico subsequente ou reduzir a sua toxicidade (Metcalf \& Eddy, 2003).

Estudos nacionais e internacionais realizados por Queiroz et al. (2011), Moravia et al. (2011), Cotman e Gotvajn (2010) e Zhang et al. (2012) que utilizaram a reação de Fenton como técnica de tratamento do lixiviado de Gericinó/RJ, CTR Belo Horizonte/MG, Aterro Municipal da Eslovênia e Wuhan na China, respectivamente, obtiveram eficiências maiores que $60 \%$ na remoção da DQO.

O presente trabalho visa avaliar técnicas de tratamento para um lixiviado gerado em um aterro controlado situado no Estado do Rio de Janeiro, de forma a minimizar o impacto ocasionado pela elevada concentração de matéria orgânica e, dessa forma, aumentar a sua biodegradabilidade para que possa ser tratado em sistemas biológicos. Esse aterro operou por 22 anos e na época do estudo, já estava encerrado (desde 2012). A recirculação do lixiviado era realizada sob o maciço de resíduos enterrados, através de caminhões com aspersores acoplados na traseira, que coletavam o lixiviado no tanque de recepção.

\section{MATERIAS E MÉTODOS}

As tecnologias utilizadas como tratamento do lixiviado do aterro controlado avaliadas nesse trabalho foram: Coagulação/Floculação, utilizando como coagulante o cloreto férrico $\left(\mathrm{FeCl}_{3}\right)$, adsorção com carvão ativado em pó (CAP) e Reação de Fenton, e após todos os tratamentos foram executados testes de biodegradabilidade aeróbia em cada um dos efluentes. O fluxograma da Figura 1 demonstra as sequências de tratamento estudadas.

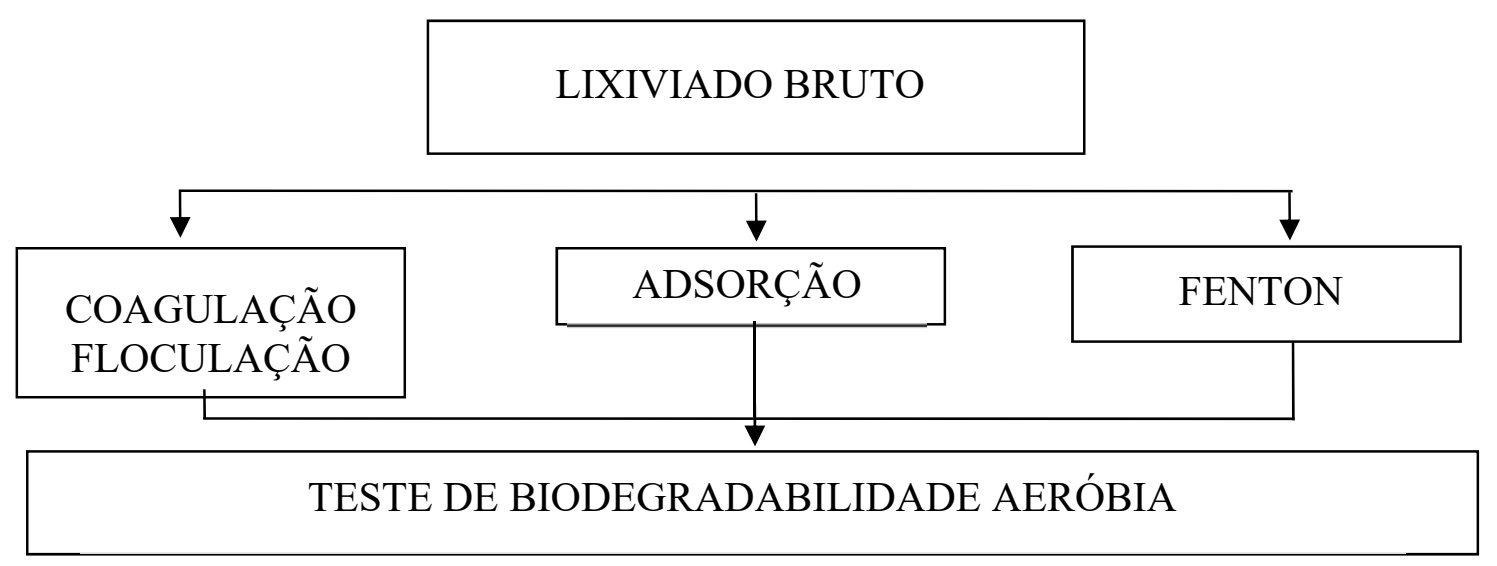

Figura 1. Metodologia de tratamento do lixiviado.

\subsection{Coleta do efluente}

Amostras de lixiviado foram coletadas no tanque de recepção de um aterro controlado. $\mathrm{O}$ aterro encontra-se atualmente encerrado após 22 anos de operação, quando recebeu diariamente 180 toneladas de resíduos sólidos domésticos e 1,5 toneladas de resíduos provenientes da área de saúde (Vasconcelos, 2014). As coletas foram realizadas sempre no mesmo ponto e em diferentes épocas do ano, o que possibilitou avaliar as mudanças nas características do lixiviado. As amostras eram coletadas em bombonas de 20 litros. Geralmente, a coleta era realizada no final da tarde, o efluente era preservado na geladeira até o dia seguinte, e era levado para o laboratório, onde já eram iniciadas as análises. Os parâmetros de caracterização foram: $\mathrm{pH}$, cloreto, DQO, Demanda Bioquímica de Oxigênio (DBO), Carbono Orgânico Total (COT), Absorbância a $254 \mathrm{~nm}\left(\mathrm{Abs}_{254}\right)$ e cor, segundo metodologia constante no Standard Methods (APHA, 2005). 


\subsection{Processo de coagulação/floculação}

$\mathrm{O}$ processo de coagulação/floculação foi realizado em duas etapas: definição do $\mathrm{pH}$ (volume de $300 \mathrm{~mL}$ de lixiviado, concentração do coagulante $200 \mathrm{mg} \mathrm{FeCl}_{3} \mathrm{~L}^{-1}$ ), no qual variouse o pH (4 a 9) a fim de encontrar o ponto ótimo de eficiência de remoção de DQO e redução da Abs254 (parâmetro que avalia a presença de substâncias orgânicas, em sua maioria orgânicos aromáticos, que absorvem luz em comprimento de onda de $254 \mathrm{~nm}$, região do UV - APHA, 2005); e variação da concentração de cloreto férrico (100 a $600 \mathrm{mg} \mathrm{L}^{-1}$ a partir do $\mathrm{pH}$ ótimo) avaliando os mesmos parâmetros.

Todos os ensaios foram realizados no Jar Test (Nova Ética), a uma rotação de 150 rpm pelo tempo de 1 minuto durante a mistura rápida e a 20 minutos durante a mistura lenta a $20 \mathrm{rpm}$.

\subsection{Adsorção com carvão ativado em pó}

Foi utilizado CAP da marca Carbomafra, (Tipo: $117 \mathrm{CB}$ AS no40), de origem vegetal e fabricação nacional. A metodologia do tratamento utilizada foi adaptada de Maia (2012), onde se variaram as concentrações de carvão em 0,$1 ; 0,4 ; 0,7 ; 1,0 ; 3,0 ; 5,0 \mathrm{~g} \mathrm{~L}^{-1}$. Os testes foram executados em erlenmeyers com efluente e CAP, deixando em contato por 24 horas em constante agitação de $250 \mathrm{rpm}$ em mesa agitadora a $25^{\circ} \mathrm{C}$. Após as 24 horas, as amostras foram filtradas em papel filtro e feitas análises de COT, DQO e Abs254.

\subsection{Reação de Fenton}

Foram fixadas, inicialmente, as relações DQO lixiviado bruto: $\mathrm{H}_{2} \mathrm{O}_{2}$ em 1:1, 1:2 e 1:5. Para cada relação, foram utilizadas diferentes razões $\mathrm{Fe}^{+2}: \mathrm{H}_{2} \mathrm{O}_{2}$, a saber, 1:3, 1:5 e 1:10.

Após duas horas, as amostras foram retiradas do meio reacional, alcalinizadas com solução de hidróxido de sódio $\left(40 \mathrm{~g} \mathrm{~L}^{-1}\right)$ e decantadas para análise. $\mathrm{O}$ teor de peróxido residual foi analisado através de análise colorimétrica de reação com metavanadato de amônio, visto que ele causa interferência na determinação da DQO (Costa et al., 2015).

\subsection{Testes de biodegradabilidade aeróbia}

A metodologia utilizada para o teste de biodegradabilidade aeróbia foi Método de Zahn-Wellens, adotada pela OECD - Organisation For Economic Co-Operation And Development (1992), e consiste em analisar a biodegradabilidade aeróbia de um determinado efluente. Foram utilizados biorreatores (erlenmeyer de $2 \mathrm{~L}$ ) que continham: $500 \mathrm{~mL}$ de meio mineral, uma certa quantidade de efluente que atingisse uma DQO de $1.000 \mathrm{mg} \mathrm{L}^{-1}$, e um volume específico de lodo de uma ETE (Estação de Tratamento de Esgoto) situada no Estado do Rio de Janeiro, para atingir uma concentração de 4,0 $\mathrm{g} \mathrm{L}^{-1}$ de Sólidos Suspensos Voláteis (SSV). Foram utilizadas bombas de aquário com difusores para o fornecimento de ar dissolvido. Para o bloqueio da luz, foi utilizado papel laminado envolto nos erlenmeyers; e para o controle de $\mathrm{pH}$, foram utilizadas soluções de $\mathrm{NaOH}\left(40 \mathrm{~g} \mathrm{~L}^{-1}\right)$ e $\mathrm{H}_{2} \mathrm{SO}_{4}\left(50 \mathrm{~g} \mathrm{~L}^{-1}\right)$ (Soares, 2013).

Os testes de biodegradabilidade foram realizados em duplicata, e conduzidos em biorreatores alimentados da seguinte forma:

- Branco (somente meio mineral + lodo);

- Controle: solução de glicose com DQO equivalente a $1000 \mathrm{mg} \mathrm{L}^{-1}+$ lodo.

- Lixiviado bruto + lodo;

- Lixiviado tratado por Coagulação/Floculação + lodo;

- Lixiviado tratado por Adsorção em Carvão Ativado + lodo; e

- Lixiviado tratado por Fenton + lodo. 
O ensaio em branco foi utilizado para descartar possíveis contribuições que o lodo e o meio mineral possam gerar no sistema reacional e a solução de glicose foi utilizada para servir como controle do lodo, para verificar se o mesmo se apresenta ativo.

\section{RESULTADOS E DISCUSSÃO}

\subsection{Caracterização do lixiviado}

Os resultados de caracterização obtidos das amostras de lixiviado bruto coletadas no tanque de retenção do aterro controlado em diferentes épocas do ano estão apresentados na Tabela 1.

Tabela 1. Caracterização do lixiviado bruto do aterro controlado (RJ).

\begin{tabular}{lccccccc}
\hline Parâmetros & $21 / 03 / 13$ & $22 / 08 / 13$ & $09 / 01 / 14$ & $23 / 01 / 14$ & $20 / 02 / 14$ & $20 / 03 / 14$ & $29 / 05 / 14$ \\
\hline $\mathrm{pH}$ & 8,4 & 8,5 & 8,3 & 8,6 & 8,5 & 8,2 & 8,2 \\
$\begin{array}{l}\text { Cloreto } \\
\left(\mathrm{mg} \mathrm{L}^{-1}\right)\end{array}$ & 791 & 1.641 & 1.377 & 1.321 & 2.001 & 1.732 & 1.608 \\
$\begin{array}{l}\text { DQO } \\
\left(\mathrm{mg} \mathrm{L}^{-1}\right)\end{array}$ & 550 & 7.400 & 2.023 & 1.920 & 2.836 & 5.875 & 3.041 \\
$\begin{array}{l}\text { Cor } \\
\left(\mathrm{mgPtCo} \mathrm{L}^{-1}\right)\end{array}$ & 6.800 & 5.700 & 6.783 & 6.416 & 6.300 & 5.083 & 6.504 \\
$\begin{array}{l}\text { Abs } 254 \\
\mathrm{COT}_{\left(\mathrm{mg} \mathrm{L}^{-1}\right)}\end{array}$ & $\mathrm{NA}$ & 17,9 & 16,5 & 15,1 & 16,5 & 46,06 & 25,16 \\
$\begin{array}{l}\text { DBO } \\
\left(\mathrm{mg} \mathrm{L}^{-1}\right)\end{array}$ & 154 & 506 & NA & 441,8 & 486,2 & 751,5 & 706,5 \\
\hline \begin{tabular}{l} 
Clima \\
\hline
\end{tabular} & Chuvoso & Seco & Seco & Chuvoso & Seco & Seco & Seco \\
\hline
\end{tabular}

NA: Não Avaliado.

Os resultados mostram que este lixiviado apresenta características de um efluente de difícil tratamento, em especial devido à elevada concentração de matéria orgânica recalcitrante (baixa relação DBO/DQO, 0,23). Essa análise indica que o efluente precisaria passar por um pré-tratamento antes de ser tratado biologicamente, para aumentar a relação a biodegradabilidade.

Segundo Gomes (2009), estas características confirmam que o lixiviado é oriundo de resíduos mais estabilizados, pois nestas condições há a presença de ácidos fúlvicos e húmicos, compostos de difícil degradação biológica. Esses ácidos contribuem para a coloração escura do lixiviado, que pôde ser observada em todas as amostras e é confirmada pelos valores elevados de cor e Abs254.

Esse resultado já era esperado, visto que o aterro encontra-se fechado desde 2012 e que a linha de alimentação do tanque de retenção é oriunda de células mais antigas. Pode ser observado, também, o pH levemente básico superior a 8 em todas as coletas. 


\subsection{Coagulação/Floculação}

A Tabela 2 ilustra os resultados obtidos durante a otimização do $\mathrm{pH}$ e concentração do coagulante durante a realização do processo de coagulação/floculação.

Tabela 2. Resultados dos testes de otimização de $\mathrm{pH}$ e concentração de coagulante $\left(\mathrm{FeCl}_{3}\right)$ utilizando lixiviado com DQO inicial de $1031 \mathrm{mg} \mathrm{L}^{-1}$ Abs254 de 17,9 e pH inicial de 8,5. Condições dos ensaios: mistura rápida, $150 \mathrm{rpm}$ por 1 minuto e mistura lenta, $20 \mathrm{rpm}$ por 20 minutos.

\begin{tabular}{|c|c|c|c|c|c|}
\hline \multicolumn{6}{|c|}{ Otimização do pH } \\
\hline $\mathrm{pH}$ & $\begin{array}{l}\text { Coagulante } \\
\left(\mathrm{mg} \mathrm{FeCl}_{3} \mathrm{~L}^{-1}\right)\end{array}$ & $\mathrm{Abs}_{254}$ & $\begin{array}{c}\text { Redução da } \\
\operatorname{Abs}_{254}(\%)\end{array}$ & $\begin{array}{c}\mathrm{DQO} \\
\left(\mathrm{mg} \mathrm{L}^{-1}\right)\end{array}$ & $\begin{array}{l}\text { Eficiência de } \\
\text { remoção de } \\
\text { DQO }(\%)\end{array}$ \\
\hline 4 & \multirow{6}{*}{200} & 0,48 & 97,3 & 756 & 26,7 \\
\hline 5 & & 0,58 & 96,7 & 858 & 16,7 \\
\hline 6 & & 0,55 & 96,9 & 906 & 12,1 \\
\hline 7 & & 0,66 & 96,3 & 921 & 10,6 \\
\hline 8 & & 0,82 & 95,4 & 913 & 11,5 \\
\hline 9 & & 0,82 & 95,4 & 917 & 11,1 \\
\hline \multicolumn{6}{|c|}{ Otimização da concentração de coagulante } \\
\hline $\begin{array}{c}\text { Coagulante } \\
\left(\mathrm{mg} \mathrm{FeCl}_{3} \mathrm{~L}^{-1}\right)\end{array}$ & $\mathrm{pH}$ & $\mathrm{Abs}_{254}$ & $\begin{array}{c}\text { Redução da } \\
\operatorname{Abs}_{254}(\%)\end{array}$ & $\begin{array}{c}\mathrm{DQO} \\
\left(\mathrm{mg} \mathrm{L}^{-1}\right)\end{array}$ & $\begin{array}{c}\text { Eficiência de } \\
\text { remoção de } \\
\text { DQO }(\%)\end{array}$ \\
\hline 100 & \multirow{6}{*}{4,0} & 0,49 & 97,3 & 898 & 12,9 \\
\hline 200 & & 0,48 & 97,3 & 752 & 27,1 \\
\hline 300 & & 0,47 & 97,4 & 795 & 22,9 \\
\hline 400 & & 0,44 & 97,5 & 830 & 19,5 \\
\hline 500 & & 0,40 & 97,8 & 849 & 17,7 \\
\hline 600 & & 0,40 & 97,8 & 728 & 29,4 \\
\hline
\end{tabular}

Na primeira etapa, o pH igual a 4 foi a condição que apresentou a maior eficiência na remoção da DQO e Abs254. Destaca-se a elevada redução da Abs254 em pH 4 de, aproximadamente, 97\%. Dessa maneira, esse valor de $\mathrm{pH}$ foi escolhido para etapa seguinte.

A concentração de cloreto férrico que apresentou a maior eficiência de remoção em relação à DQO foi $600 \mathrm{mg} \mathrm{L}^{-1}$, porém as concentrações de 200 e $300 \mathrm{mg} \mathrm{L}^{-1}$ também apresentaram resultados significativos, na de 22 a $27 \%$ de remoção. Entretanto, para aplicação de $300 \mathrm{mg} \mathrm{FeCl}_{3} \mathrm{~L}^{-1}$ foi alcançada remoção de $64 \%$ de COT e para $200 \mathrm{mg} \mathrm{FeCl} \mathrm{L}^{-1}, 38,9 \%$ (resultados não mostrados na Tabela 2). Sendo assim, como melhores condições de tratamento desse lixiviado, foram eleitos o $\mathrm{pH}$ igual a 4 e $300 \mathrm{mg} \mathrm{FeCl}_{3} \mathrm{~L}^{-1}$.

Marañón et al. (2008), utilizando $400 \mathrm{mg} \mathrm{FeCl}_{3} \mathrm{~L}^{-1}$, obtiveram uma eficiência de remoção de DQO de 28,1\%, valor próximo aos encontrados nesse estudo. Esse resultado decorre, provavelmente, devido à operação do aterro, pois o aterro espanhol operava do mesmo modo que $o$ aterro do presente trabalho.

De acordo com os trabalhos de Ferreira e Campos (2014) e Gewehr (2012), que obtiveram $60 \%$ e $63 \%$ de eficiência de remoção de DQO, respectivamente, pode-se verificar que os resultados dos testes de coagulação/floculação obtidos neste estudo, em geral, apresentaram uma baixa eficiência de remoção de DQO, porém, esse fato pode ser devido à composição química variada do lixiviado e dos resíduos enterrados. 


\subsection{Adsorção em carvão ativado}

A Tabela 3 ilustra os resultados dos ensaios de adsorção usando o carvão ativado em pó em diferentes concentrações.

Alguns ensaios mostraram significativas eficiências de remoção de DQO, sendo as melhores obtidas com as concentrações de 3 e $5 \mathrm{~g} \mathrm{~L}^{-1}$ de CAP. Aghamohammadi et al. (2007) e Kargi e Uygur (2004) utilizaram $3 \mathrm{~g} \mathrm{~L}^{-1}$ e $5 \mathrm{~g} \mathrm{~L}^{-1}$, respectivamente, de CAP (de diferentes procedências) para tratar o lixiviado. Ambos os autores encontraram uma eficiência de remoção de $49 \%$ de DQO, um pouco abaixo do que encontrado no presente trabalho, mas mesmo assim mostra que a adsorção ao CAP pode ser uma alternativa promissora para a remoção de matéria orgânica do efluente em questão.

Tabela 3. Resultados dos testes de adsorção com carvão ativado em pó após 24 horas de contato e sob agitação de $250 \mathrm{rpm}$, Carbomafra, (Tipo: $117 \mathrm{CB}$ AS nº40).

\begin{tabular}{ccc}
\hline $\begin{array}{c}\text { CAP } \\
\left(\mathrm{g} \mathrm{L}^{-1}\right)\end{array}$ & $\begin{array}{c}\text { DQO } \\
\left(\mathrm{mg} \mathrm{L}^{-1}\right)\end{array}$ & $\begin{array}{c}\text { Eficiência de remoção } \\
\text { de DQO }(\%)\end{array}$ \\
\hline Lixiviado bruto & 2600 & -- \\
0,1 & 1740 & 33,1 \\
0,4 & 1404 & 46,0 \\
0,7 & 1309 & 49,7 \\
1,0 & 1304 & 49,8 \\
3,0 & 976 & 62,5 \\
5,0 & 805 & 69,0 \\
\hline
\end{tabular}

Em geral, os ensaios com carvão ativado mostraram significativas eficiências de remoção, porém quando foram utilizadas dosagem maiores, 3 e $5 \mathrm{~g} \mathrm{~L}^{-1}$ de CAP, foram alcançadas as melhores eficiências na remoção da DQO.

De acordo com o Cotman e Gotvajn (2010), o tratamento utilizando carvão ativado apresenta boa eficiência de remoção da DQO, onde os autores obtiveram $86 \%$ de remoção usando uma dosagem de $50 \mathrm{~g} \mathrm{~L}^{-1}$. Entretanto, deve-se considerar que o emprego de dosagens elevadas pode dificultar a aplicação dessa técnica de tratamento no aterro, considerando os custos elevados de um sistema de tratamento em escala real e a regeneração do CAP.

\subsection{Reação de Fenton}

Para a avaliação da remoção da matéria orgânica, inicialmente foram estabelecidas as relações DQOLIXIVIADO BRUTO: $\mathrm{H}_{2} \mathrm{O}_{2}$ e para cada valor dessa relação foram variadas as relações de $\mathrm{Fe}^{+2}: \mathrm{H}_{2} \mathrm{O}_{2}$. O tempo de reação $(2 \mathrm{~h})$ e o $\mathrm{pH}$ (3) foram fixados em valores usuais de acordo com a literatura. Em uma segunda etapa, foi avaliada a relação DQOLIXIVIADO BRUTo: $\mathrm{H}_{2} \mathrm{O}_{2}$ de 1:0,5. A Tabela 4 ilustra os resultados de eficiência de remoção da DQO para os experimentos utilizando o Reativo de Fenton.

As porcentagens de remoção da DQO foram todas maiores que $50 \%$ em todas as condições testadas e percebe-se que quanto menor a quantidade de ferro na reação, menor a remoção de DQO e maiores as concentrações de peróxido residual no efluente. Esse cenário se dá porque o ferro é o catalisador responsável pela formação dos radicais hidroxila, os quais favorecem a oxidação da matéria orgânica.

Observando-se os resultados, quando a quantidade de peróxido aumenta (relação DQO: $\mathrm{H}_{2} \mathrm{O}_{2}$ de 1:2 e 1:5), aumentam-se as quantidades de reagentes, mas a eficiência de remoção de DQO não acompanha na mesma proporção. Então, para confirmar os resultados anteriores foi 
utilizada uma nova amostra de lixiviado e realizados ensaios com relação DQO: $\mathrm{H}_{2} \mathrm{O}_{2}$ igual a 1:1 e 1:0,5, mantendo-se a proporção de $\mathrm{Fe}: \mathrm{H}_{2} \mathrm{O}_{2}$ de 1:3. Os resultados podem ser observados na última linha da Tabela 4.

Tabela 4. Resultados dos ensaios do Reativo de Fenton utilizando pH igual a 3 e $2 \mathrm{~h}$ de reação.

\begin{tabular}{|c|c|c|c|c|c|c|c|}
\hline $\begin{array}{l}\text { DQO } \\
\text { LIXIVIADO } \\
\text { BRUTO } \\
\left(\mathrm{mg} \mathrm{L}^{-1}\right)\end{array}$ & $\begin{array}{l}\text { DQO: } \\
\mathrm{H}_{2} \mathrm{O}_{2}\end{array}$ & $\begin{array}{c}\mathrm{Fe}: \\
\mathrm{H}_{2} \mathrm{O}_{2}\end{array}$ & $\begin{array}{c}\mathrm{H}_{2} \mathrm{O}_{2} \\
\left(\mathrm{mg} \mathrm{L}^{-1}\right)\end{array}$ & $\begin{array}{l}\mathrm{Fe}^{2+} \\
\left(\mathrm{mg} \mathrm{L}^{-1}\right)\end{array}$ & $\begin{array}{c}\mathrm{H}_{2} \mathrm{O}_{2} \text { residual } \\
\left(\mathrm{mg} \mathrm{L}^{-1}\right)\end{array}$ & $\begin{array}{l}\text { DQO final* } \\
\left(\mathrm{mg} \mathrm{L}^{-1}\right)\end{array}$ & $\begin{array}{l}\text { Eficiência de } \\
\text { remoção de } \\
\text { DQO }(\%)\end{array}$ \\
\hline \multirow{6}{*}{2023} & \multirow{3}{*}{$1: 1$} & $1: 3$ & \multirow{3}{*}{2.023} & 674,3 & 78 & 436 & 78,4 \\
\hline & & $1: 5$ & & 404,6 & 190 & 581 & 71,3 \\
\hline & & $1: 10$ & & 202,3 & 570 & 847 & 58,1 \\
\hline & \multirow{3}{*}{$1: 2$} & $1: 3$ & \multirow{3}{*}{4.046} & $1.348,7$ & 53 & 358 & 82,3 \\
\hline & & $1: 5$ & & 809,2 & 523 & 521 & 74,2 \\
\hline & & $1: 10$ & & 404,6 & 597 & 484 & 76,0 \\
\hline \multirow{3}{*}{1702} & \multirow{3}{*}{$1: 5$} & $1: 3$ & \multirow{3}{*}{8.510} & $2.836,7$ & 68 & 343 & 79,8 \\
\hline & & $1: 5$ & & $1.702,0$ & 452 & 340 & 80,0 \\
\hline & & $1: 10$ & & 851,0 & 990 & 381 & 77,6 \\
\hline \multirow{2}{*}{2490} & $1: 1$ & $1: 3$ & 2.490 & 830,0 & 181 & 655 & 73,7 \\
\hline & $1: 0,5$ & $1: 3$ & 1.245 & 415,0 & 146 & 896 & 64,0 \\
\hline
\end{tabular}

*corrigida, descontando a parcela referente ao peróxido residual.

Comparando os dois testes feitos para relação DQO/ $\mathrm{H}_{2} \mathrm{O}_{2}$ igual a $1 / 1$ pode-se observar que o ensaio que utilizou menor quantidade de $\mathrm{H}_{2} \mathrm{O}_{2}$ resultou em elevada concentração de peróxido residual, diferentemente do obtido no primeiro ensaio. O resultado de remoção de DQO para a relação DQO: $\mathrm{H}_{2} \mathrm{O}_{2}$ igual a 1:1 foi similar ao anterior (com outra amostra de lixiviado). Porém, para a menor concentração de peróxido, a remoção de DQO foi diminuída em quase dez pontos percentuais.

Outros autores obtiveram em suas pesquisas eficiências maiores que $80 \%$, no entanto, utilizaram relações Fe: $\mathrm{H}_{2} \mathrm{O}_{2}$ maiores. Como exemplo, Costa et al. (2015) obteve eficiência de remoção de DQO igual a $88 \%$ utilizando a relação $\mathrm{Fe}^{2+}: \mathrm{H}_{2} \mathrm{O}_{2}$ igual a 1:5 com tempo de reação de 60 minutos.

\subsection{Testes de biodegradabilidade aeróbia}

Para avaliar se os tratamentos pesquisados tiveram efeito na biodegradabilidade do lixiviado, foram realizados testes de biodegradabilidade aeróbia para o efluente tratado por coagulação/floculação, adsorção em carvão ativado e Fenton, nas suas melhores condições. Conforme Tabela 5, os resultados apresentados são médias da duplicata realizada. Ressalta-se que os resultados não diferiram em menos de $10 \%$ entre eles e todos os ensaios foram realizados em amostras diferentes de lixiviado.

O lixiviado bruto apresentou resultados diferentes no teste de biodegradabilidade. Isso se deve ao fato de que para cada teste uma nova amostra era coletada, e os resultados evidenciam a heterogeneidade das características do lixiviado.

No teste 1, o lixiviado bruto apresenta uma boa biodegradabilidade (80\%), superior ao lixiviado pré-tratado (54\%). Isso demonstra que a amostra de lixiviado bruto se apresentou 
muito mais biodegradável que o efluente do processo de coagulação/floculação, e que o mesmo não foi capaz de aumentar a biodegradabilidade do lixiviado.

Para o teste 2 , utilizando efluente após o CAP, a partir do $13^{\circ}$ dia a biodegradabilidade dos efluentes tratados começou a aumentar. A condição com concentração de $5 \mathrm{~g} \mathrm{~L}^{-1}$ de carvão gerou os melhores resultados. Ao fim do tratamento com CAP houve uma remoção de $69 \%$ da DQO, sendo obtidos valores de biodegradabilidade próximos aos do lixiviado bruto $(23 \%)$. Esse resultado comprova que o tratamento não alterou a biodegradabilidade do efluente.

Tabela 5. Resultado de biodegradabilidade aeróbia em 29 dias.

\begin{tabular}{|c|c|c|}
\hline Testes & Amostras e condições do processo & $\begin{array}{l}\text { Biodegradabilidade } \\
\text { aeróbia após } 29 \text { dias (\%) }\end{array}$ \\
\hline \multirow[b]{2}{*}{1} & Lixiviado Bruto (coletado em 22/08/2013) & 80 \\
\hline & $\begin{array}{l}\text { Lixiviado após coagulação/floculação } \\
\left(\mathrm{pH}=4 \text { e } 300 \mathrm{mg} \mathrm{FeCl}_{3} \mathrm{~L}^{-1}\right)\end{array}$ & 54 \\
\hline \multirow{3}{*}{2} & Lixiviado Bruto (coletado em 20/03/2014) & 23 \\
\hline & Lixiviado após adsorção com $3 \mathrm{~g} \mathrm{CAP} / \mathrm{L}$ & 17 \\
\hline & Lixiviado após adsorção com $5 \mathrm{~g}$ CAP/L & 23 \\
\hline \multirow[b]{2}{*}{3} & Lixiviado Bruto (coletado em 29/05/2014) & 5 \\
\hline & $\begin{array}{l}\text { Lixiviado após Reativo de Fenton } \\
\left(\text { DQO } / \mathrm{H}_{2} \mathrm{O}_{2} \text { de } 1 / 1 \mathrm{e} \mathrm{Fe}^{+2} / \mathrm{H}_{2} \mathrm{O}_{2} \text { de } 1 / 3\right)\end{array}$ & 25 \\
\hline
\end{tabular}

Para os ensaios com efluente tratado pelo processo Fenton (DQO: $\mathrm{H}_{2} \mathrm{O}_{2}$ de 1:1 e Fe: $\mathrm{H}_{2} \mathrm{O}_{2}$ de 1:3), a biodegradabilidade foi maior que o lixiviado bruto. Destaca-se, neste caso, a maior recalcitrância do lixiviado bruto perante aos anteriores. Apesar disso, a reação de Fenton conseguiu aumentar a biodegradabilidade do lixiviado.

\section{CONCLUSÕES}

Ao todo foram coletadas sete amostras de lixiviado em diferentes épocas do ano no tanque de retenção de um aterro controlado no Estado do Rio de Janeiro, o que permitiu avaliar o comportamento da composição do líquido ao longo do tempo. Por se tratar de um aterro controlado, onde as condições de operação do aterro não são as ideiais, percebeu-se grande variabilidade nas características do lixiviado.

Após definidas as condições ótimas de tratamento do lixiviado por coagulação/floculação ( $\mathrm{pH}=4$ e $300 \mathrm{mg} \mathrm{FeCl}_{3} \mathrm{~L}^{-1}$ ), obteve-se uma remoção de 22,9\% da DQO e 64\% do COT.

Duas condições ótimas do processo de adsorção em carvão ativado em pó no tratamento do lixiviado foram estabelecidas, com 3 e $5 \mathrm{~g} \mathrm{~L}^{-1}$ de carvão, e essas condições obtiveram eficiências de remoção da DQO de $62,5 \%$ e $69 \%$, respectivamente.

A Reação de Fenton foi o tratamento que apresentou as melhores porcentagens de remoção, obtendo eficiências de remoção de DQO entre 58,12 a 82,30\%, sendo a escolhida como melhor condição a que utilizou as relações DQO: $\mathrm{H}_{2} \mathrm{O}_{2}$ igual a $1: 1$ e $\mathrm{Fe}: \mathrm{H}_{2} \mathrm{O}_{2}$ igual $1: 3$ e obteve $78,42 \%$ de remoção, pois esta utilizou menor concentração de ferro e peróxido de hidrogênio.

Nos testes de biodegradabilidade aeróbia, a Reação de Fenton levou a um aumento da biodegradabilidade do lixiviado nas condições de DQO $: \mathrm{H}_{2} \mathrm{O}_{2}$ de $1: 1$ e $\mathrm{Fe}^{2+}: \mathrm{H}_{2} \mathrm{O}_{2}$ de 1:3. 


\section{AGRADECIMENTOS}

À FAPERJ (Fundação Carlos Chagas Filho de Amparo à Pesquisa do Estado do Rio de Janeiro) pelo auxílio financeiro para a pesquisa.

\section{REFERÊNCIAS}

AGHAMOHAMMDI, N.; AZIZ, H. A; ISA, M.H.; ZINATIZADEH, A. A. Powdered activated carbon augmented activated sludge process for treatment of semi-aerobic landfill leachate using response surface methodology. Bioresource Technology, v. 98, n.18, , p. 35103578, 2007. http://dx.doi.org/10.1016/j.biortech.2006.11.037

AMERICAN PUBLIC HEALTH ASSOCIATION - APHA. Standard Methods for the Examination of Water and Wastewater. 21. ed. Washington, DC, 2005.

CHEIBUB, A.F.; CAMPOS, J.C; FONSECA, F.V. Removal of COD from a stabilized landfill leach ate by physicochemical and Advanced Oxidative Process Journal of Environmental Science and Health Part A Toxic/Hazardous Substances \& Environmental Engineering, v. 49, n. 14, p. 1718-1726, 2014. http://dx.doi.org/10.1080/10934529.2014.951259

COSTA, F. M.; CAMPOS, J. C.; FONSECA, F. V.; BILA, D. M. Tratamento de lixiviados de aterros de resíduos sólidos utilizando Processos Fenton e Foto-Fenton Solar. Revista Ambiente \& Água, v.10, n.1, 2015. http://dx.doi.org/10.4136/ambi-agua.1483

COTMAN, M.; GOTVAJN, A.Z. Comparison of different physic-chemical methods for the removal of toxicants landfill leachate. Journal of Hazardous Materials, v. 178, n. 1-3, p. 208-305, 2010. http://dx.doi.org/10.1016/j.jhazmat.2010.01.078

DENG, J.; ENGLEHARDT, J.D. Treatment of landfill leachate by the Fenton process. Water Research, v. 40, n.20, p. 3683-3694, 2006. http://dx.doi.org/10.1016/j.watres.2006.08.009

FENTON, H. J. H. Oxidation of tartaric acid in presence of iron. Journal of the Chemical Society, Transactions, v. 65, n. 141, p. 899-910, 1894. http://dx.doi.org/10.1039/CT8946500899

FERREIRA, D. S.; CAMPOS, J.C. Estudo comparativo da coagulação-floculação e eletrocoagulação no tratamento de lixiviado de Aterro Sanitário. In: SIMPOSIO ITALOBRASILEIRO DE ENGENHARIA SANITÁRIA E AMBIENTAL, 12., 19-21 maio. Natal. Anais... Natal: ABES, 2014. 1 CD-ROM.

GEWEHR, A.G. Tratamento por Coagulação/Floculação de Lixiviado Bruto de Aterro Sanitário com e sem Pré-Tratamento Biológico em Reator Sequencial em Batelada. 2012. 163f. Dissertação (Mestrado em Recursos Hídricos e Saneamento) - Universidade Federal do Rio Grande do Sul, Porto Alegre, 2012.

GOMES, L. P. (Org) PROSAB, Programa de Pesquisa em Saneamento Básico. Edital 5. Resíduos sólidos: estudos de caracterização e tratabilidade de lixiviados de aterros sanitários para as condições brasileiras. Rio de Janeiro: ABES, 2009. 362 p.

KARGI, F.; UYGUR, A. Biological nutrient removal from pre-treated landfill leach ate in a sequencing batch reactor. Journal of Environmental Management, v. 71, n.1, p. 9-14, 2004. http://dx.doi.org/10.1016/j.jenvman.2004.01.002 
LI, W.; HUA, T.; ZHOU, Q.; ZHANG, S.; LI., F. Treatment of stabilized landfill leachate by the combined process of coagulation/flocculation and powder activated carbon adsorption. Desalination, v. 264, n. 1-2, p. 56-62, 2010.

http://dx.doi.org/10.1016/j.desal.2010.07.004

MAIA, L. S. Uso de carvão ativado em pó no tratamento biológico de lixiviado de aterro de resíduos. 2012. 177f. Dissertação (Mestrado em Tecnologia de Processos Químicos e Bioquímicos) - Universidade Federal do Rio de Janeiro, Rio de Janeiro, 2012.

MARAÑÓN, E.; CASTRILLÓN, L.; FERNÁNDEZ-NAVA, Y.; FERNÁNEZ-MÉNDEZ, A.; FERNÁNDEZ-SANCHÉZ, A. Coagulation-flocculation as a pretreatment processat a landfill leach ate nitrification-denitrification plant. Journal of Hazardous Materials, v. 156, n. 1-3, p. 538-544, 2008. http://dx.doi.org/10.1016/j.jhazmat.2007.12.084

METCALF \& EDDY INC. Wastewater engineering: treatment and reuse. 4th ed. New York: McGraw-Hill, 2003. 1819p.

MORAVIA, W. G.; LANGE, L. C.; AMARAL, M. C. S. Avaliação de processo oxidativo avançado pelo reagente de fenton em condições otimizadas no tratamento de lixiviado de aterro sanitário com ênfase em parâmetros coletivos e caracterização do lodo gerado. Química Nova, v. 34, n. 8, 2011.

ORGANIZATION FOR ECONOMIC CO-OPERATION AND DEVELOPMENT - OECD. OECD Guideline for Testing of Chemicals. Zahn-Wellens. Paris, 1992. Disponível em: https://www.oecd.org/env/ehs/testing/E302B.pdf . Acesso em: 11 jun.2016.

QUEIROZ, L. G.; FREIRE, L. F. A.; ARAUJO, F. V. F.; YOKOYAMA, L.; CAMPOS, J. C. Estudo do processo Fenton e Foto-Fenton no tratamento de lixiviados de aterros sanitários. In: CONGRESSO BRASILEIRO DE ENGENHARIA SANITÁRIA E AMBIENTAL, 26., 2011, Porto Alegre. Anais... Rio de Janeiro: ABES, 2011. v. 1. p. 1 5.

SÁ, L. F.; JUCÁ, F. T.; SOBRINHO, M. A. M. Tratamento do lixiviado de aterro sanitário usando destilador solar. Revista Ambiente \& Água, v.07, n.1, 2012. http://dx.doi.org/10.4136/ambi-agua.81

SOARES, C. I. S. Ensaio de biodegradabilidade aeróbia para apoio à operação de Contactor Biológico Rotatório tratando lixiviados. 2013. 114f. Dissertação (Mestrado em Engenharia Civil) - Universidade do Vale dos Sinos, São Leopoldo, 2013.

VASCONCELOS, D.V. Estudo da tratabilidade do lixiviado gerado no aterro controlado de Volta Redonda(RJ). 2014. 66f. Dissertação (Mestrado em Engenharia Ambiental) - Escola Politécnica, Universidade Federal do Rio de Janeiro, Rio de Janeiro, 2014.

ZHANG, H.; WU, X.; LI, X. Oxidation and coagulation removal of COD from landfill leachate by Fered-Fenton process. The Chemical Engineering Journal, v. 210, n.1, p.188-194, 2012. http://dx.doi.org/10.1016/j.cej.2012.08.094 